\title{
Selection of Selected Flight Attendants Using MCDM-AHP and ELECTRE Method
}

\begin{abstract}
Akmaludin
STMIK Nusa Mandiri Jakarta

Jakarta, Indonesia

akmaludin.akm@nusamandiri.ac.id

\author{
Frans Edward Schaduw \\ Universitas Bina Sarana Informatika \\ Jakarta, Indonesia \\ frans.fes@bsi.ac.id
}

\author{
Achmad Sumbaryadi \\ Universitas Bina Sarana Informatika \\ Jakarta, Indonesia \\ achmad.acs@bsi.ac.i.d
}

Abstract - The number of business interests nowadays, many people use flight services to reach distant areas and must be traveled by very complex flight services. Such conditions have resulted in a large number of airlines requiring flight attendants to service their passengers on the plane. So that the right method is needed to carry out the selection process for flight attendants, the ELECTRE method is one solution that can be done for the flight attendant's selection process. The results obtained from the selection process of flight attendants without a score, because they have used the elimination process through threshold concordance and threshold discordance as follows, out of nine candidates for flight attendants who have passed the selection are flight attendants-3, flight attendants- 6 and flight attendants-7, while others are not acceptable. So that through the results of the selection that has been done with the collaboratin AHP and ELECTRE method, by seeing the results obtained from aggregate matrices dominant, So there were 3 flight attendants who passed the selection, and 6 flight attendants were eliminated.
\end{abstract}

\author{
Heru Purwanto \\ Universitas Bina Sarana Informatika \\ Jakarta, Indonesia \\ heru.hrp@bsi.ac.id
}

Keywords - AHP, ELECTRE, Elimination, Flight attendants, MCDM.

\section{INTRODUCTION}

To complete flight conditions, a number of flight attendants who have preparedness are needed, not only from the mentallity aspect (Udayana et al., 2016), but from aspects of physical health conditions that have the most important role. Aspects of physical health must be done in selecting flight attendants, because physical health conditions strongly support the smooth implementation of flight. Health conditions that are very much needed are such as dental health $(\mathrm{KG})$ which greatly affects the balance, eye health $(\mathrm{KM})$ which greatly affects vision, weight (BB) which must be balanced with the ideal level of the body, foot length (PK) which affect the height of body texture, height (TB) adjusted to the standard needs of a flight attendant, and age or age (US) which affects the agility and speed of service to the passengers of the flight.

Testing of the six physical conditions related to the selection of flight attendants is part of the criteria of this study, which is tested using the Analytic Hierarchy Process (AHP) method which is used to determine preference weights in terms of determining preference weighting criteria, while data processing for entry selection flight attendants use the ELECTREE method, because both AHP and ELECTRE methods are one of the methods related to the ranking process (Wu \& Huang, 2011), (Yang, Xu, Qiu, \& Wang, 2013) which are Multi-

criteria Decision Making (MCDM) (Mary \& Suganya, 2016). Can it provide tangible evidence that these two methods can be collaborated in the selection of selected flight attendants with optimal results and what kind of decisions are made.

It has been known before, a number of flight attendants who are data processing as dataset, they are flight attendants in the good category, and who from those who have the best assessment is needed by collaboration testing using AHP and ELECTRE methods (Ermatita, Sri Hartati, Wardoyo, \& Harjoko, 2011) of approximately nine people in accordance with the six criteria for preferences measurement. 


\section{LiterATURE REVIEW}

From several literature sources that can be used as a reference for the supports discussion about selecting the best flight attendants, they will provide insights and insights that complement the content of the research that has been carried out.

\section{A. Analytic Hierarchy Process (AHP).}

The Analytic Hierarchical Process (AHP) method has an interest in determining selection and evaluation (Farkas, 2007) in priority terms, using existing rules (Ishizaka \& Lusti, 2006) as well as (1) performing decomposition stages into hierarchy models, (2) providing weighting techniques from each criteria level and alternative, (3) the process of testing consistency with the weighting results measured through the acquisition of the eigenvector, (4) the synthesis process at each criteria level and alternative, and (5) determining the level measured from the measured weight of each alternative.

Determination of weights measured through the process of acquiring the eigenvector (Vargas, 2010) is processed in the form of two dimensions arranged in the form of matrices, paying attention to the orderly arrangement of matrices in (Figure 1). The arrangement of matrices must pay attention to the layout of the matrices element $\mathrm{A}$ in row (i) and column (j).

$$
\left[\begin{array}{ccccccc}
a_{1,1} & a_{1,2} & a_{1,3} & \ldots & \ldots & \ldots & a_{1, j} \\
a_{2,1} & a_{2,2} & a_{2,3} & \ldots & \ldots & \ldots & a_{2, j} \\
a_{3,1} & a_{3,2} & a_{3,3} & \ldots & \ldots & \ldots & a_{3, j} \\
& & & & & & \\
\ldots & \ldots & \ldots & \ldots & \ldots & \ldots & \\
& & & & & & \\
a_{i, 1} & a_{i, 2} & a_{i, 3} & \ldots & \ldots & \ldots & a_{i, j}
\end{array}\right]
$$

Figure 1. Arrangement of matrices.

Pairwise matrices can be consistent if they meet the transitive and reciprocal rules (Chupiphon \& Janjira, 2016), while the transitive formula can be seen in (equation-1) and the reciprocal formula can be seen in (equation-2) below:

$$
\begin{gathered}
a_{i j}=a_{i k} \cdot a_{k j} \\
a_{i j}=\frac{1}{a_{j i}}
\end{gathered}
$$

Thus the multiplication of matrices can be done by consistency index (CI) and consistency ratio (CR) test, whether the results obtained can be accepted or rejected, consistency test can use (equation-3) and (equation-4):

$$
C I=\frac{\lambda_{\max }-N}{N-1}
$$

$$
C R=\frac{C I}{R I}
$$

To determine the amount of $\mathrm{CR}$, a random index quantity (Saaty, 2008) is needed in the table arrangement shown in (Table 1).

Table 1. Radom Index

\begin{tabular}{cc}
\hline Ordo & RI \\
\hline 1 & 0 \\
2 & 0 \\
3 & 0.58 \\
4 & 0.90 \\
5 & 1.12 \\
6 & 1.24 \\
7 & 1.32 \\
8 & 1.41 \\
9 & 1.45 \\
0 & 1.49 \\
11 & 1.51 \\
12 & 1.58 \\
\hline
\end{tabular}

\section{B. ELECTRE.}

ELECTRE method is one of the methods used to rank by using the concept of elimination (Yang et al., 2013), namely by comparing between two alternatives based on criteria that are parameters of measurement and selected based on the threshold magnitude (Govindan \& Grigore, n.d.) found in dominant matrices.

The rules of play or stages are carried out using the ELECTRE method (Chen \& Hung, 2008) as follows: (1) determine the dataset to be normalized, (2) the normalization process is weighted from the predetermined one, (3) determine the set for concordance and discordance, (4) arrange matrices concordance and discordance, (5) look for the threshold acquisition process to do the elimination stages of matrices elements both concordance and discordance, (6) Look for concordace dominant matrices and discordace dominant matrices, (7) Find matrices aggregate to determine the ranking of each selected alternative.

A number of equations can be used from each stage of ELECTRE as follows, from the acquisition of the dataset (Mary \& Suganya, 2016), (Govindan \& Grigore, n.d.) the treated must be normalized first, using (equation-5).

$$
r_{i j}=\frac{x_{i j}}{\sqrt{\sum_{i=1}^{m} x_{i j}^{2}}} \text { untuk } \mathrm{i}=1,2,3, \ldots, \mathrm{m} \text { dan } \mathrm{j}=1,2,3, \ldots, \mathrm{n} .
$$

Whereas to find the process of determining weighted normalization, by multiplying the weight set by each dataset table element in matrices normalization, so that the comparison between each row matrices can be processed with the matrices compared to get the set of matrices concordance and set of matrices discordance, as for formulas that can be used follow (equation-6) and (equation-7). 


$$
C_{k l}=\sum_{j \in c_{k l}} W_{j}
$$

With the following conditions:

$$
\begin{aligned}
& C_{k l}=\left\{j, y_{k j} \geq y_{l j}\right\}, \text { untuk } j=1,2,3, \ldots, n \\
&-\max \left\{\left|V_{k j}-V_{l j}\right|\right\}_{j \in D_{k l}} \\
& d_{k l}=\frac{\max \left\{\left|V_{k j}-V_{l j}\right|\right\}_{\forall j}}{}
\end{aligned}
$$

With the following conditions:

$$
D_{k l}=\left\{j, y_{k j}<y_{i j}\right\}, \text { untuk } j=1,2,3, \ldots, n
$$

After knowing the set of matrices concordance and set of matrices discordance, it will easily be known the amount of threshold concordance and threshold discordance (Yang et al., 2013), (De, 2002), (Mary \& Suganya, 2016) as a measure to determine the stages of the elimination process from each element matrices concordance and discordance, the formulas that can be used take note (equation-8) and (equation-9) below:

$$
\begin{gathered}
c=\frac{\sum_{k=1}^{n} \sum_{l=1}^{n} c_{k l}}{m *(m-1)} \\
\underline{d}=\frac{\sum_{k=1}^{n} \sum_{l=1}^{n} d_{k l}}{m *(m-1)}
\end{gathered}
$$

Towards the final stage, the process of determining aggregate dominant matrices to determine the ranking of a number of alternatives is available, namely ranking for flight attendants for the needs of airlines.

\section{Proposed Method}

The selection process with the ELECTRE method, especially in ranking against alternatives to the concept of elimination, is a concept that is able to provide optimal solutions for the process of selecting flight attendants for each flight. The algorithm that can be used for the selection process for selected flight attendant personnel, pay attention (Figure 2).

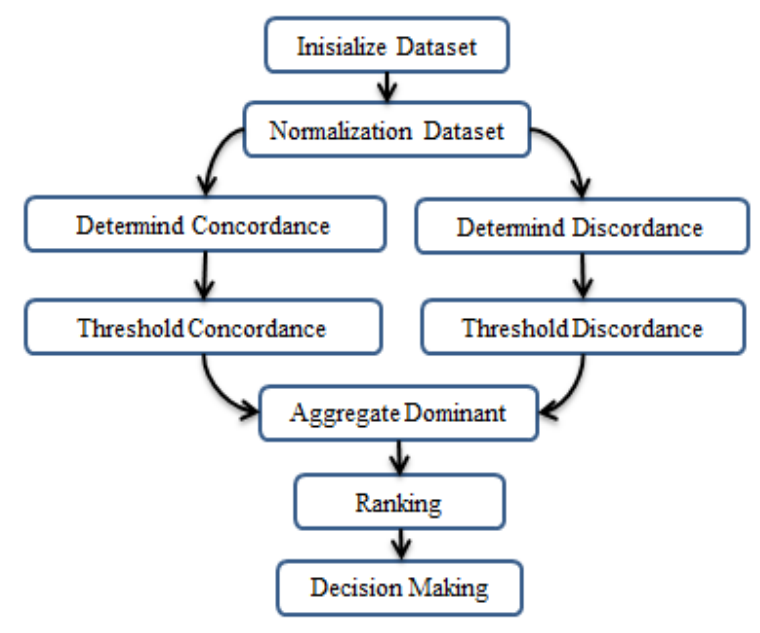

Figure 2. ELECTRE Algorithm.

The uniqueness of the use of Algorithm from the ELECTRE method is that the threshold is determined scientifically from each set arranged in a matrix both concordance and discordance. Therefore the rating process in ELECTRE has a reference that adapts to the condition of the dataset built based on the provisions of the criteria, the meaning of that there is no standard and barometer that must be followed by certain provisions.

\section{RESUlt AND Discussion}

The preference function used for weight measurement is processed through the AHP method, which is used as the weighting criterion in the ELECTRE method, of the 48 respondents used to fill the accumulated questionnaire using AHP, criteria are formed in the arrangement of pairwise matrices, as shown in (Table 2).

Table 2. Pairwise matrices criteria.

\begin{tabular}{ccccccc}
\hline Main Criteria & $K G$ & $K M$ & $B B$ & $P K$ & $T B$ & US \\
\hline KG & 1.000 & 2.725 & 2.621 & 4.051 & 1.700 & 2.941 \\
KM & 0.367 & 1.000 & 2.303 & 2.902 & 3.026 & 2.439 \\
BB & 0.382 & 0.434 & 1.000 & 1.989 & 2.357 & 2.119 \\
PK & 0.247 & 0.345 & 0.503 & 1.000 & 1.117 & 1.886 \\
TB & 0.588 & 0.331 & 0.424 & 0.895 & 1.000 & 1.504 \\
US & 0.340 & 0.410 & 0.472 & 0.530 & 0.665 & 1.000 \\
\hline
\end{tabular}

The data shown in (Table 2) are obtained through very strict stages, then processed by the algebra matrices method formed with five stages of the optimal eigenvector acquisition process, note (Table 3 ), which is used as a preference in the ELECTRE method. 
Table 3. Eigenvector as preferences.

\begin{tabular}{cccc}
\hline Criteria & Row Count & \multicolumn{2}{c}{ Egenvector } \\
\hline KG & 457620385064752000000000000000000000000000000000000000.0000 & 0.341 \\
KM & 3135131418620800000000000000000000000000000000000000.0000 & 0.234 \\
BB & 20626129605361900000000000000000000000000000000000000.0000 & 0.154 \\
PK & 1256444227568150000000000000000000000000000000000000.0000 & 0.094 \\
TB & 1363721189231940000000000000000000000000000000000000.0000 & 0.102 \\
US & 10132227084267600000000000000000000000000000000000000.0000 & 0.076 \\
\hline Total & 13407334355031400000000000000000000000000000000000000.000 & 1.000 \\
\hline
\end{tabular}

The eigenvector value is said to be optimal if the condition of Consistency Ratio (CR) $<0.1$. Note (Figure 3) testing of eigenvector which is the multiplication of master matrices with optimal eigenvector process using algebra matrices.

$$
\begin{aligned}
& {\left[\begin{array}{llllll}
1.000 & 2.725 & 2.621 & 4.051 & 1.700 & 2.941 \\
0.367 & 1.000 & 2.303 & 2.902 & 3.026 & 2.439 \\
0.382 & 0.434 & 1.000 & 1.989 & 2.357 & 2.119 \\
0.247 & 0.345 & 0.503 & 1.000 & 1.117 & 1.886 \\
0.588 & 0.331 & 0.424 & 0.895 & 1.000 & 1.504 \\
0.340 & 0.410 & 0.472 & 0.530 & 0.665 & 1.000
\end{array}\right] \times\left[\begin{array}{l}
0.341 \\
0.234 \\
0.154 \\
0.094 \\
0.102 \\
0.076
\end{array}\right]=\left[\begin{array}{l}
2.156 \\
1.477 \\
0.972 \\
0.592 \\
0.643 \\
0.477
\end{array}\right]} \\
& \text { Lamda Max } \quad 6.318 \\
& \text { Consistensi Index } \quad 0.064 \\
& \text { Consistency Ratio } \quad 0.051<10 \% \text { (Accetptable) }
\end{aligned}
$$

Figure 3. Eigenvector using Algebra Matrices.

The test results with the application of expert choice have similar results with the process of algebra matrices, note (Figure 4) with inconsistency number is $5 \%$ and 0 missing judgments, the result can be seen at (Figure-4). CR results of less than 10 percent illustrate that decisions are acceptable.

\section{Priorities with respect to: \\ Goal: Cirteria for the fight attend.}

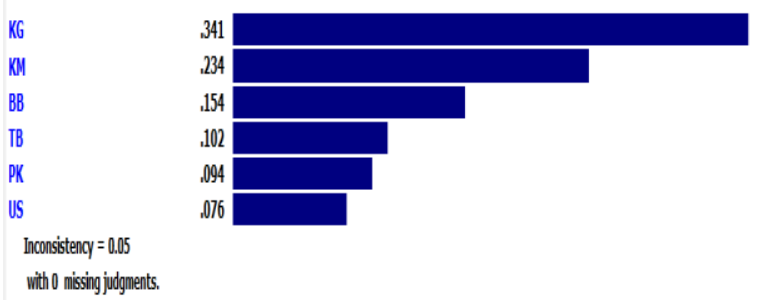

Figure 4. Eigenvector using Expert choices.

The eigenvector value used as a preference and simplified into two digits, starting from the criteria $\mathrm{KG}=0.341 ; \mathrm{KM}=0.234 ; \mathrm{BB}=0.154 ; \mathrm{TB}=0.102$;
$\mathrm{PK}=0.094 ;$ and $\mathrm{US}=0.076$. The preference obtained through the AHP method will be used in the ELECTRE method as a measure accepted or rejected against alternative flight attendants. With the ELECTRE method, it starts from the acquisition of data sets that are processed through the selection stages of six criteria as a barometer for selecting selected flight attendants consisting of nine flight attendants with six criteria that are used (1) dental health examination, (2) eye health examination, ( 3) examination of body condition, (4) measurement of leg length, (5) height measurement, and (5) age aspect.

The parameter scale of each criterion has a range of 1-5. It can be seen from the dataset that each criterion gives different results, but having the same total score for each flight attendant is 20 (twenty), this is the highest measure of value and is said to be the selection of selected flight attendants. Describe the dataset produced from 9 (nine) flight attendants accordingly (Table 4). The selected stewardesses have the same highest grade criteria, so we need the right selection method to be selected from them through the weight criteria obtained from the AHP method.

Table 4. Dataset

\begin{tabular}{lcccccc}
\hline Alt & C1 & C2 & C3 & C4 & C5 & C6 \\
\hline P1 & 3 & 3 & 5 & 5 & 2 & 2 \\
P2 & 5 & 3 & 4 & 5 & 1 & 2 \\
P3 & 4 & 5 & 3 & 1 & 2 & 5 \\
P4 & 3 & 2 & 5 & 4 & 5 & 1 \\
P5 & 3 & 5 & 2 & 4 & 1 & 5 \\
P6 & 2 & 4 & 5 & 4 & 4 & 1 \\
P7 & 5 & 2 & 4 & 1 & 5 & 3 \\
P8 & 5 & 5 & 1 & 2 & 5 & 2 \\
P9 & 2 & 5 & 2 & 3 & 4 & 4 \\
\hline
\end{tabular}

For the stages of data processing, of course using a method, namely ELECTRE, then the data must be normalized first to determine the range of each data and the position of the data. Normalization results obtained using (equation-5) as shown in (Table 5). To be processed further by the ELECTRE method, the normalization stage is needed as a placement of the range of data used. Thus the position of the data is arranged regularly and can be processed by the ELECTRE method.

From the results of normalization obtained, the use of the preferences obtained such as (Figure-3) and (Figure-4) using AHP and the Expert Choice Application are the best ways to determine the normalization weight, 
Table 5. Normalization.

\begin{tabular}{ccccccc}
\hline Weight & 0.341 & 0.234 & 0.154 & 0.094 & 0.102 & 0.076 \\
Criteria & K1 & K2 & K3 & K4 & K5 & K6 \\
\hline P1 & 0.267 & 0.252 & 0.447 & 0.470 & 0.185 & 0.212 \\
P2 & 0.445 & 0.252 & 0.358 & 0.470 & 0.092 & 0.212 \\
P3 & 0.356 & 0.420 & 0.268 & 0.094 & 0.185 & 0.530 \\
P4 & 0.267 & 0.168 & 0.447 & 0.376 & 0.462 & 0.106 \\
P5 & 0.267 & 0.420 & 0.179 & 0.376 & 0.092 & 0.530 \\
P6 & 0.178 & 0.336 & 0.447 & 0.376 & 0.370 & 0.106 \\
P7 & 0.445 & 0.168 & 0.358 & 0.094 & 0.462 & 0.318 \\
P8 & 0.445 & 0.420 & 0.089 & 0.188 & 0.462 & 0.212 \\
P9 & 0.178 & 0.420 & 0.179 & 0.282 & 0.370 & 0.424 \\
\hline
\end{tabular}

With the discovery of normalization, the role of preferences through the process of acquiring eigenvectors can determine weighted normalization which is a normalization multiplication with preferences and the results can be seen in (Table 6).

Table 6. Weight Normalization.

\begin{tabular}{ccccccc}
\hline & K1 & K2 & K3 & K4 & K5 & K6 \\
\hline P1 & 0.091 & 0.059 & 0.069 & 0.044 & 0.019 & 0.016 \\
P2 & 0.152 & 0.059 & 0.055 & 0.044 & 0.009 & 0.016 \\
P3 & 0.122 & 0.098 & 0.041 & 0.009 & 0.019 & 0.040 \\
P4 & 0.091 & 0.039 & 0.069 & 0.035 & 0.047 & 0.008 \\
P5 & 0.091 & 0.098 & 0.028 & 0.035 & 0.009 & 0.040 \\
P6 & 0.061 & 0.078 & 0.069 & 0.035 & 0.038 & 0.008 \\
P7 & 0.152 & 0.039 & 0.055 & 0.009 & 0.047 & 0.024 \\
P8 & 0.152 & 0.098 & 0.014 & 0.018 & 0.047 & 0.016 \\
P9 & 0.061 & 0.098 & 0.028 & 0.026 & 0.038 & 0.032 \\
\hline
\end{tabular}

The basis for finding the concordance set and discordance set is weighted normalization compared to each line element one with the other row elements with equation- 6 and equation- 7 , the results in (Table 9) which will form matrices concordance and matrices discordance with the order of nine.

The matrices concordance shown in (Table 7) is arranged to form a square.

Table 7. Concordance Matrices.

\begin{tabular}{cccccccccc}
\hline Alt & P1 & P2 & P3 & P4 & P5 & P6 & P7 & P8 & P9 \\
\hline P1 & 0.000 & 0.256 & 0.248 & 0.403 & 0.349 & 0.511 & 0.481 & 0.248 & 0.589 \\
P2 & 0.341 & 0.000 & 0.589 & 0.744 & 0.589 & 0.511 & 0.328 & 0.248 & 0.589 \\
P3 & 0.651 & 0.411 & 0.000 & 0.651 & 0.597 & 0.651 & 0.309 & 0.229 & 0.571 \\
P4 & 0.102 & 0.256 & 0.349 & 0.000 & 0.256 & 0.443 & 0.248 & 0.248 & 0.691 \\
P5 & 0.309 & 0.309 & 0.094 & 0.309 & 0.000 & 0.651 & 0.403 & 0.323 & 0.511 \\
P6 & 0.336 & 0.489 & 0.349 & 0.234 & 0.256 & 0.000 & 0.481 & 0.248 & 0.248 \\
P7 & 0.519 & 0.177 & 0.597 & 0.417 & 0.597 & 0.519 & 0.000 & 0.229 & 0.597 \\
P8 & 0.677 & 0.336 & 0.537 & 0.651 & 0.443 & 0.752 & 0.328 & 0.000 & 6.000 \\
P9 & 0.411 & 0.411 & 0.195 & 0.309 & 0.102 & 0.309 & 0.403 & 0.323 & 0.000 \\
\hline
\end{tabular}

While the results of matrices discordance obtained from the discordance set can be seen in
(Table 8). Both table matrices concordance and discordance as a reference to determine the amount of threshold value which is the basic benchmark for passing through the process of elimination, where the values of matrices concordance and discordance will be eliminated directly.

Tabel 8. Matrices discordance.

\begin{tabular}{lccccccccc}
\hline Alt & C1 & C2 & C3 & C4 & C5 & C6 & C7 & C8 & C9 \\
\hline P1 & 0.000 & 1.000 & 1.000 & 1.438 & 1.000 & 1.000 & 1.000 & 1.000 & 1.000 \\
P2 & 0.155 & 0.000 & 1.000 & 1.000 & 1.000 & 1.000 & 1.000 & 1.000 & 1.000 \\
P3 & 1.467 & 1.467 & 0.000 & 0.880 & 1.000 & 0.587 & 1.000 & 1.174 & 1.000 \\
P4 & 0.696 & 1.617 & 1.000 & 0.000 & 1.000 & 1.000 & 1.000 & 1.000 & 1.000 \\
P5 & 1.718 & 2.531 & 0.356 & 1.174 & 0.000 & 0.880 & 1.000 & 1.565 & 1.000 \\
P6 & 0.426 & 3.234 & 1.000 & 0.240 & 1.000 & 0.000 & 1.000 & 1.000 & 1.000 \\
P7 & 1.000 & 0.938 & 0.568 & 1.651 & 0.426 & 1.651 & 0.000 & 1.000 & 1.000 \\
P8 & 0.938 & 0.703 & 1.000 & 0.935 & 1.000 & 1.000 & 0.701 & 0.000 & 1.000 \\
P9 & 1.101 & 3.234 & 3.234 & 1.718 & 0.284 & 1.718 & 1.550 & 5.694 & 0.000 \\
\hline
\end{tabular}

Thus matrices dominant concordance and dominant discordance matrices are easily obtained by using equation- 8 and equation- 9 , with the results can be seen in (Table 10) and (Table 11) which is the process of determining the dominant aggregate matrices. It is necessary to know the threshold concordace is 0.49 which is obtained through matrices concordance and threshold discordance is 1.19 obtained from discordance matrices. The value under the threshold will be zero, on the contrary it is worth one.

Table 9. Set of concordance and discordance.

\begin{tabular}{lcccccc}
\hline Bobot & 0.34 & 0.23 & 0.15 & 0.09 & 0.10 & 0.08 \\
\hline $\mathrm{C}(1,2)$ & -0.061 & 0.000 & 0.014 & 0.000 & 0.009 & 0.000 \\
$\mathrm{C}(1,3)$ & -0.030 & -0.039 & 0.028 & 0.035 & 0.000 & -0.024 \\
$\mathrm{C}(1,4)$ & 0.000 & 0.020 & 0.000 & 0.009 & -0.028 & 0.008 \\
$\mathrm{C}(1,5)$ & 0.000 & -0.039 & 0.041 & 0.009 & 0.009 & -0.024 \\
$\mathrm{C}(1,6)$ & 0.030 & -0.020 & 0.000 & 0.009 & -0.019 & 0.008 \\
$\mathrm{C}(1,7)$ & -0.061 & 0.020 & 0.014 & 0.035 & -0.028 & -0.008 \\
$\mathrm{C}(1,8)$ & -0.061 & -0.039 & 0.055 & 0.026 & -0.028 & 0.000 \\
$\mathrm{C}(1,9)$ & 0.030 & -0.039 & 0.041 & 0.018 & -0.019 & -0.016 \\
$\mathrm{C}(2,1)$ & 0.061 & 0.000 & -0.014 & 0.000 & -0.009 & 0.000 \\
$\mathrm{C}(2,3)$ & 0.030 & -0.039 & 0.014 & 0.035 & -0.009 & -0.024 \\
$\mathrm{C}(2,4)$ & 0.061 & 0.020 & -0.014 & 0.009 & -0.038 & 0.008 \\
$\mathrm{C}(2,5)$ & 0.061 & -0.039 & 0.028 & 0.009 & 0.000 & -0.024 \\
$\mathrm{C}(2,6)$ & 0.091 & -0.020 & -0.014 & 0.009 & -0.028 & 0.008 \\
$\mathrm{C}(2,7)$ & 0.000 & 0.020 & 0.000 & 0.035 & -0.038 & -0.008 \\
$\mathrm{C}(2,8)$ & 0.000 & -0.039 & 0.041 & 0.026 & -0.038 & 0.000 \\
$\mathrm{C}(2,9)$ & 0.091 & -0.039 & 0.028 & 0.018 & -0.028 & -0.016 \\
$\mathrm{C}(3,1)$ & 0.030 & 0.039 & -0.028 & -0.035 & 0.000 & 0.024 \\
$\mathrm{C}(3,2)$ & -0.030 & 0.039 & -0.014 & -0.035 & 0.009 & 0.024 \\
$\mathrm{C}(3,4)$ & 0.030 & 0.059 & -0.028 & -0.026 & -0.028 & 0.032 \\
$\mathrm{C}(3,5)$ & 0.030 & 0.000 & 0.014 & -0.026 & 0.009 & 0.000 \\
$\mathrm{C}(3,6)$ & 0.061 & 0.020 & -0.028 & -0.026 & -0.019 & 0.032 \\
$\mathrm{C}(3,7)$ & -0.030 & 0.059 & -0.014 & 0.000 & -0.028 & 0.016 \\
$\mathrm{C}(3,8)$ & -0.030 & 0.000 & 0.028 & -0.009 & -0.028 & 0.024 \\
$\mathrm{C}(3,9)$ & 0.061 & 0.000 & 0.014 & -0.018 & -0.019 & 0.008 \\
$\mathrm{C}(4,1)$ & 0.000 & -0.020 & 0.000 & -0.009 & 0.028 & -0.008 \\
$\mathrm{C}(4,2)$ & -0.061 & -0.020 & 0.014 & -0.009 & 0.038 & -0.008 \\
$\mathrm{C}(4,3)$ & -0.030 & -0.059 & 0.028 & 0.026 & 0.028 & -0.032
\end{tabular}




\begin{tabular}{|c|c|c|c|c|c|c|}
\hline & & & & & & \\
\hline & & & & & & \\
\hline & & & & 26 & & \\
\hline & & & & 18 & & \\
\hline & & & & 00 & & \\
\hline & & 039 & 41 & .009 & & \\
\hline & D61 & 0.039 & & .009 & & \\
\hline & 0 & 0.0 & -0.0 & & & \\
\hline & & 0.05 & & 000 & & \\
\hline & & & & 00 & & \\
\hline & 1 & 0 & & 20 & & 01 \\
\hline 5 & -0.061 & 0.000 & 0.0 & 018 & & \\
\hline & & & & & & \\
\hline & & & & & & \\
\hline & & D & 0 & - & & 0.00 \\
\hline & & & & & & 03 \\
\hline 5,4$)$ & 0.03 & & 0.0 & .000 & & 0.00 \\
\hline & 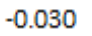 & & 0. & 000 & & \\
\hline & & & & 026 & & - \\
\hline 8) & & & & & & . \\
\hline 59) & 000 & 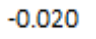 & 0 & 9 & & \\
\hline & & & & & & \\
\hline & & & & & & \\
\hline & & & & & & - \\
\hline & 00 & & & & & \\
\hline & & & & & & - \\
\hline & & & & & & \\
\hline & & & & & & DO \\
\hline & & & & & & \\
\hline & & & & & & \\
\hline & & & & & & \\
\hline & & & & & & - \\
\hline & & & & & & 0.00 \\
\hline & & & & & & \\
\hline & & & & & & \\
\hline & & & & & & - \\
\hline & & & & & & $-c$ \\
\hline & & & & & & \\
\hline & & & & & & \\
\hline & 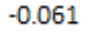 & & & & & OC \\
\hline & & & & & & \\
\hline & & & & & & OC \\
\hline & & & & & & \\
\hline & & & & & & \\
\hline & & & & & & \\
\hline
\end{tabular}

(Table 9) illustrates development results from the acquisition of weight normalize, to place data in the position of two-dimensional matrices. that are adjusted to the amount of processed data for each row associated with each weight normalize. The data generated after compared with other data, thus giving a picture of a matrices that can be arranged according to the applicable matrices rules and in the end two matrices are formed in the form of concordance and matrices discordance.
Table 10. Concordance dominant matrices.

\begin{tabular}{ccccccccc}
\hline P1 & P2 & P3 & P4 & P5 & P6 & P7 & P8 & P9 \\
\hline 0 & 0 & 0 & 0 & 0 & 1 & 0 & 0 & 1 \\
\hline 0 & 0 & 1 & 1 & 1 & 1 & 0 & 0 & 1 \\
\hline 1 & 0 & 0 & 1 & 1 & 1 & 0 & 0 & 1 \\
\hline 0 & 0 & 0 & 0 & 0 & 0 & 0 & 0 & 1 \\
\hline 0 & 0 & 0 & 0 & 0 & 1 & 0 & 0 & 1 \\
\hline 0 & 1 & 0 & 0 & 0 & 0 & 0 & 0 & 0 \\
\hline 1 & 0 & 1 & 0 & 1 & 1 & 0 & 0 & 1 \\
\hline 1 & 0 & 1 & 1 & 0 & 1 & 0 & 0 & 1 \\
\hline 0 & 0 & 0 & 0 & 0 & 0 & 0 & 0 & 0 \\
\hline
\end{tabular}

Table 11. Discordance dominant matrices.

(Tables 10) and (Table 11) are the results obtained from the development of relations in each row, for the row to form concordance matrices and for the colomn will form discordance matrices.

\begin{tabular}{ccccccccc}
\hline P1 & P2 & P3 & P4 & P5 & P6 & P7 & P8 & P9 \\
\hline 0 & 0 & 0 & 1 & 0 & 0 & 0 & 0 & 0 \\
\hline 0 & 0 & 0 & 0 & 0 & 0 & 0 & 0 & 0 \\
\hline 1 & 1 & 0 & 0 & 0 & 0 & 0 & 0 & 0 \\
\hline 0 & 1 & 0 & 0 & 0 & 0 & 0 & 0 & 0 \\
\hline 1 & 1 & 0 & 0 & 0 & 0 & 0 & 1 & 0 \\
\hline 0 & 1 & 0 & 0 & 0 & 0 & 0 & 0 & 0 \\
\hline 0 & 0 & 0 & 1 & 0 & 1 & 0 & 0 & 0 \\
\hline 0 & 0 & 0 & 0 & 0 & 0 & 0 & 0 & 0 \\
\hline 0 & 1 & 1 & 1 & 0 & 1 & 1 & 1 & 0 \\
\hline
\end{tabular}

The two tables with entries in the form of binary numbers, will be used as a reference to determine the chosen alternative, especially to find out the flight attendants received and rejected through such a long process.

By using the binary multiplication process between matrices dominant concordance and matrices dominant discordance, matrices aggregate will be obtained as shown in (Table 12).

Tabel 12. Aggregate dominan matrices.

\begin{tabular}{ccccccccccc}
\hline Alt (i) & \multicolumn{10}{c}{ Elimination Number } \\
\hline P1 & 0 & 0 & 0 & 0 & 0 & 0 & 0 & 0 & 0 & 0 \\
\hline P2 & 0 & 0 & 0 & 0 & 0 & 0 & 0 & 0 & 0 & 0 \\
\hline P3 & 1 & 0 & 0 & 0 & 0 & 0 & 0 & 0 & 0 & 1 \\
\hline P4 & 0 & 0 & 0 & 0 & 0 & 0 & 0 & 0 & 0 & 0 \\
\hline P5 & 0 & 0 & 0 & 0 & 0 & 0 & 0 & 0 & 0 & 0 \\
\hline P6 & 0 & 1 & 0 & 0 & 0 & 0 & 0 & 0 & 0 & 1 \\
\hline P7 & 0 & 0 & 0 & 0 & 0 & 1 & 0 & 0 & 0 & 1 \\
\hline P8 & 0 & 0 & 0 & 0 & 0 & 0 & 0 & 0 & 0 & 0 \\
\hline P9 & 0 & 0 & 0 & 0 & 0 & 0 & 0 & 0 & 0 & 0 \\
\hline
\end{tabular}

\section{CONCLUSION AND Suggestion}

The results obtained from the combination of the Analytic Hierarchy Process (AHP) method and ELECTRE elimination method, were able to provide optimal results in determining the selection of flight attendants for an airline in need. The conclusions that 
can be made are that for the flight attendants received from nine people, it turns out that only three people were accepted namely flight attendant-3, flight attendant-6, and 7-flight attendant, of which three flight attendants were accepted by the ELECTRE method that did not provide a numerical value each alternative, because the elimination stage has been carried out in comparing between one alternative to another in the threshold stage.

\section{ACKNOWLEDGMENT}

Thank you for the smooth running of this article, of course for the STMIK Nusa Mandiri campus, it has provided encouragement and motivation, it cannot be forgotten to the SinkrOn journal which has provided an opportunity for publication and publication of this article.

\section{REFERENCES}

Chen, C. T., \& Hung, W. Z. (2008). Applying Fuzzy Linguistic Variable and ELECTRE Method in $R \& D$ project Evaluation and Selection. 999 1003.

Chupiphon, S., \& Janjira, P. (2016). Compariosn Of MCDM Methods For Intercrop Selection In Rubber Plantations Chutiphon. Journal of ICT, l(1), 165-182.

De, E. (2002). Multicriteria modelling for a repair contract problem based on utility and the ELECTRE I method. Journal of Management Mathematics, (13), 29-37.

Ermatita, Sri Hartati, Wardoyo, R., \& Harjoko, A. (2011). Electre Methods in Solving Group Decision Support System Bioinformatics on Gene Mutation Detection Simulation. International Journal of Computer Science and Information Technology, 3(1), 40-52. https://doi.org/10.5121/ijcsit.2011.3104

Farkas, A. (2007). The analysis of the principal eigenvector of pairwise comparison matrices.
Acta Polytechnica Hungarica, 4(2), 1-17.

Govindan, K., \& Grigore, M. C. (n.d.). Ranking of Third Party Logistics Provider Using Fuzzy ELECTRE II. 3-7.

Ishizaka, A., \& Lusti, M. (2006). How to derive priorities in AHP: A comparative study. Central European Journal of Operations Research, 14(4), 387-400. https://doi.org/10.1007/s10100-006-0012-9

Mary, S. A. S. A., \& Suganya, G. (2016). MultiCriteria Decision Making Using ELECTRE. Circuits and Systems, 07(06), 1008-1020. https://doi.org/10.4236/cs.2016.76085

Saaty, T. L. (2008). Decision making with the analytic hierarchy process. International Journal of Services Sciences, 1(1), 83. https://doi.org/10.1504/IJSSCI.2008.017590

Udayana, J. P., Psikologi, P. S., Psikologi, F., Udayana, U., Psikologi, P. S., Kedokteran, F., ... X, P. P. M. (2016). Efikasi Diri dan Kecerdasan Emosional dengan Perilaku Kewargaan Organisasi pada Pramugari Pramugara Maskapai X Ketut Ayumas Prasetyaningrum dan Nicholas Simarmata Abstrak. 3(1), 95-107.

Vargas, R. V. (2010). Using The Analytic Hierarchy Process (AHP) To Select And Prioritize Projects In A Portofolio. PMI Global Congress, 32(3), 1-22. Retrieved from http://www.ricardovargas.com/pt/articles/analytic-hierarchyprocess/\#english

Wu, Y., \& Huang, Y. (2011). Research on Bid Evaluation Optimal Model of Engineering Project Based on ELECTRE-II. 1(70871037), 1365-1368.

Yang, Z., Xu, Q., Qiu, X., \& Wang, H. (2013). An Applied Study on the Method for Supplier Selection with PCA and ELECTRE. 21512156. 